\title{
Two Types of Object Control in Saisiyat: A Movement-based Approach ${ }^{\mathrm{i}}$
}

\author{
Yi-ming Marc Chou
}

Graduate Institute of Linguistics, National Tsing Hua University, Taiwan

Copyright $\bigcirc 2016$ by authors, all rights reserved. Authors agree that this article remains permanently open access under the terms of the Creative Commons Attribution License 4.0 International License

\begin{abstract}
This paper analyzes the syntactic characteristics and the derivation of object control construction (OC) in Saisiyat. Saisiyat possesses two types of object control: in the canonical case, the controller occupies a structurally higher position than the controllee, while in the non-canonical case, the controller occupies a structurally lower position. We argue that the syntactic behaviours in Saisiyat, including the selection of voice, case-marking mechanisms, and subject-verb agreement, are closely related to hierarchical structures. The structure of the embedded clause in Saisiyat OC is a defective TP. This 'weak' TP cannot normally value case and govern argument. Also, it exhibits the [-Tense] feature. These two types of OC exhibit the characteristics of split-ergativity: Canonical object control strictly employs the Accusative-pattern, while non-canonical object control strictly utilizes the Ergative-pattern. We assert that the non-canonical structure employs an additional syntactic projection of Applicative Phrase in its embedded clause, which makes it syntactically different from the canonical counterpart. Based on Potsdam's[27] research on Malagasy, we propose that two types of $\mathrm{OC}$ are formed through argument movement and deletion in the fashion of Hornstein's[14] Movement Theory of Control and Nunes' [23] chain reduction principle. These configurations can account for why in Saisiyat the shared argument of OC occupies dual theta roles. However, unlike Potsdam's argument, we contend that the inadequacy of the base-generated approach is attributed to the theoretical nature of $\mathrm{PRO} /$ pro, which is incompatible with $\mathrm{OC}$, rather than the effect of locality. Finally, in order to comply with the "Last resort" and the "Greed principle" under the Minimalist Program, we further contend that the copy movement is triggered by the checking of both formal features (e.g., phi-feature and EPP) and uninterpreted features (e.g., case and tense).
\end{abstract}

Keywords Object Control, Movement, Agreement, Feature Checking, Syntax-semantic Interface, Saisiyat

\section{Setting the Stage}

This paper analyzes the syntactic characteristics and the derivation of object control construction (OC) in Saisiyat ${ }^{1}$. Object control is distinct from similar linguistic structures in several key areas. For example, in English, some similar structures, including object control construction, exceptional case-marking (ECM), raising-to-subject ${ }^{2}$ and subject control (SC), actually have different syntactic features. Please compare the following sentences.

1) $\mathrm{OC}$
a. Mary permits her to leave.
b. *Mary permits that she leave/left.
c. *Mary permits there to be a party.
d. *It permits that Mary to leave.

2) $\mathrm{ECM}$
a. Mary believes her to be innocent.
b. Mary believes that she is innocent.
c. Mary believes there to have been a party.

3) raising-to-subject
a. Mary seems to be innocent.
b. *Mary seems her to be innocent.
c. It seems that Mary is innocent.

4) $\mathrm{SC}$
a. Mary wants to leave.
b. Mary promises us to leave.
c. *Mary wants that she leave/left.
d. *It wants that Mary to leave.

Culicover[11] contends that the control verbs of OC semantically select (s-select) their dependents. The object of matrix verbs also functions as the subject of embedded verbs.

1In 2015, the Saisiyat tribe numbered 6,483. Most of them inhabit the Northwest mountain area of Taiwan. Saisiyat, an Austronesian language, consists of two dialects: Ta'ai (North dialect) and Tungho (South dialect). According to Li[19, p. 134-139] and Yeh[38, p. 44-48], these two dialects have no noticeable syntactic differences. The main differences lie in phonology and lexicon.

2 Raising structure consists of two subtypes: raising-to-subject and raising-to-object. The latter is also called Exceptional case-marking (ECM). 
This shared argument manifests in dual theta-roles: that of actor and patient. Moreover, OC exhibits trivalency (3-place predicate). That is, subject and object are the necessary arguments of control verb. Also, the control verb must take a subordinate infinitival clause as its complement, as in (1a). Similarly, though the pronoun in a matrix clause in ECM is marked by the object form, this pronoun semantically is the subject of an infinitival clause, which makes ECM present like OC, as in (2a). However, (2b) shows that ECM can employ bivalency (2-place predicate) to express the same reading. In other words, the verb of ECM can directly take a finite clause as its complement. There is no such usage in OC, as in (1b). Moreover, ECM doesn't s-select its object. Thus, ECM allows the expletive pronoun ${ }^{3}$ there to be its object, as in (2c). Conversely, OC s-selects the argument with [+person] as its object. That is there cannot be the matrix object of OC, as in (1c). Secondly, (3a) shows that raising-to-subject, like OC, can directly take an infinitival clause as its object. However, there are still subtle differences between $\mathrm{OC}$ and raising-to-subject. Raising-to-subject doesn't allow the presence of an overt pronoun. That is, the construal of trivalency is forbidden in raising-to-subject, as in ( $3 b$ ). In addition, the expletive subject it in raising-to-subject structure can undergo it-extraposition, as in (3c). This is not the case in OC, as in (1d). Finally, unlike OC, (4a-b) shows that in subject control, it is the subject of the matrix clause that functions as a shared argument. Also, in SC, it-extraposition and finite complement clause is not allowed, as shown in (4c)-(4d).

Furthermore, certain scholarly works (see Chen[6], Rosenbaum[31] and $\mathrm{Wu}[36])$ provide helpful references for this research, as they demonstrate that, the nature of the OC proposed in (5) is nontrivial cross-linguistically:

5) The nature of object control construction:

a. It consists of two clauses: the independent clause and the dependent clause.

b. The embedded clauseis non-finite: Non-finite T is defective and it cannot value case or agreement feature. $^{4}$

c. The shared argument functions as the patient of the matrix verb as well as the actor of the verb in the embedded clause.

d. Semantically, the matrix verb of object control is trivalency, including subject, object and event.

Cross-linguistically, there are two types of OC: In the

3Expletive pronoun, also called dummy pronoun or pleonastic pronoun, refers to the element which possesses syntactic function but lacks semantic content.

4Dr. H. Jonah Lin (p.c.) reminds me that non-finite is not equivalent to non-tense. Likewise, Dr. Henry Y. Chang (p.c.) also mentions that non-finite is not equal to infinitival.We argue that in English, non-finite clauses can be formed from infinitives, participles and gerunds. Though the embedded clause of OC in Saisiyat exhibits the characteristics of infinitives, Saisiyat does not possess above morphological equivalents, such as to-infinitive or V-ing in English. Therefore, we tentatively categorize the embedded clause of OC in Saisiyat asnon-finite, an upper concept, in this paper. canonical case, the controller occupies a structurally higher position than the controllee, as in (6). Conversely, in the rare non-canonical case, the controller occupies a structurally lower position, as shown in (7). The formation of the OC is related to the characteristics of the associated verb. The matrix verb of the OC controls the argument of complement clause. The overt argument is called the "controller" and is marked by a bold font while the covert argument, or the "controllee" is labeled with an italic $e$. The controller and the controllee refer to the same reference. The co-reference relationship among arguments is denoted by co-indexation.

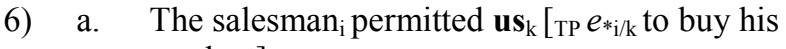
product].

b. They $y_{\mathrm{i}}$ permitted her ${ }_{\mathrm{k}}$ [тP $e_{*_{\mathrm{i} / \mathrm{k}}}$ to leave].

7) Malagasy[24, p. 328]

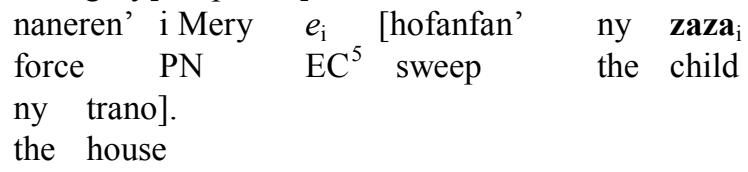

'Mary forces the child to sweep the house.'

In accordance with the framework of principles-and-parameters ( $\mathrm{P} \& \mathrm{P})$, Chomsky[8] proposes theta-Criterion which requires one-to-one mapping between theta roles and arguments. That is, every theta role assigned by a verb must be realized by some argument, and each argument may bear only a single theta role. Therefore, big PRO, a covert element, satisfies the requirement of $\mathrm{EPP}^{6}$ or theta-criterion. Although, PRO denotes the covert subject of the embedded clause in SC, some studies employ the concept of PRO to account for OC. However, we will show that Saisiyat is not suitable to a based-generated analysis (PRO \& pro). Instead, we propose employing the movement-based approach for consistent explanation. We contend that the embedded clause in Saisiyat object control construction is non-finite, and is formed by a defective TP. This TP cannot govern argument or value case normally. Also, the TP exhibits [-Tense] feature. We argue that the two types of OC in Saisiyat are formed through argument movement and deletion. In other words, the controllee, i.e., the covert argument, is not a base-generated PRO or pro. Also, the selection of voice, the case-marking mechanism, and argument licensing are closely related to syntactic structures. Saisiyat is a split-ergative language. The default syntactic structure of the two types of OC in Saisiyat also exhibits the characteristics of split-ergativity. The embedded clause of canonical OC employs a general structure, while that of non-canonical OC possesses

5The examples in the study, if non-notated, are the elicitation of my field work. The phonetic transcription and the glossary of cited data ofSaisiyat from other literatures are modified for consistency. The abbreviations of this paper follow those of the Leipzig glossing rules. Other abbreviations not included there are: $\mathrm{AV}$, actor voice; $\mathrm{PV}$, patient voice; I/BV, instrument/benefactive voice; CS, change of state; EC, empty category; PN, proper noun; RECIP, reciprocal; EXP, experience.FUT, future. PRF: perfect.

6EPP states that the sujbect position of every clause should be filled with a NP or DP. 
additional Applicative construction, which makes its syntactic behaviour different from the canonical OC.

In the remainder of this paper, we will investigate the syntax-semantic performance and the correlation of these two types of obligatory object control constructions in Saisiyat. Saisiyat morphosyntax is outlined in section 2 . The nature of Saisiyat object control is discussed in section 3 . Section 4 discusses the weakness of analyzing the Saisiyat object control using the based-generation approach (PRO \& pro) in existing literature. In section 5, Movement Theory of Control (MTC) as well as Chain reduction principles are employed to illustrate the derivation of Saisiyat object control. The hierarchical structure and synatctic derivation is depicted in section 6. Finally, concluding remarks are given in section 7 .

\section{Saisiyat Morphosyntax}

In order to understand the background for the formation of object control construction, this section outlines the grammar of Saisiyat. The word order of Saisiyat is normally SVO (n.b. most Formosan languages exhibit verbal-initial order). Saisiyat possesses a sophisticated Case system. Six different cases are employed to specify the grammatical relationship of arguments, as listed in Table 1.

Saisiyat has a fine-grained pronominal system as well. The choice of pronominal form is related to Person, Number and Case, as shown in Table 2.

In Saisiyat, the voice system can be divided into two types: actor voice (AV) and non-actor voice (NAV). Non-actor voice consists of patient voice (PV) and instrument/benefactive voice (I/BV), as given in Table 3 .

Table 1. Case system in Saisiyat (revised from [37, p. 73])

\begin{tabular}{|c|c|c|c|c|c|c|}
\hline Noun & Nominative/Absolutive & Accusative & Ergative & Dative & Possessive & Locative \\
\hline Personal & $\varnothing, \mathrm{hi}$ & $\mathrm{hi}$ & ni & 'ini & 'an-a & kan, kala \\
\hline Common & $\varnothing, \mathrm{ka}$ & $\mathrm{ka}$ & noka, no & no & 'an noka-a & ray \\
\hline
\end{tabular}

Table 2. Pronominal system in Saisiyat (revised from [37, p. 80])

\begin{tabular}{|c|c|c|c|c|c|c|c|c|}
\hline Num & Person & Case & Nom/Abs & Acc & Erg & Dat & Poss & Loc \\
\hline \multirow{3}{*}{ Sg. } & \multicolumn{2}{|c|}{$1^{\text {st }}$} & yako/yao & iyakin & ma'an & 'iniman & 'amana'a & kanman \\
\hline & \multicolumn{2}{|c|}{$2^{\text {nd }}$} & So'o/So'on & 'iso'on & niSo & 'iniSo & 'anSoaa & kanSo \\
\hline & \multicolumn{2}{|c|}{$3^{\text {rd }}$} & sia & hisia & nisia & 'inisia & 'ansiaa & kanisa \\
\hline \multirow{4}{*}{ Pl. } & \multirow{2}{*}{$1^{\mathrm{st}}$} & inc. & 'ita' & 'inimita & mita' & 'inimita' & 'anmita'a & kan'ita' \\
\hline & & exc. & yami & 'iniya'om & niya'om & 'iniya'om & 'anya'oma & kanyami \\
\hline & \multicolumn{2}{|c|}{$2^{\text {nd }}$} & moyo & 'inimon & nimon & 'inimon & 'anmoyoa & kanmoyo \\
\hline & \multicolumn{2}{|c|}{$3^{\text {rd }}$} & lasia & hilasia & nasia & 'inilasia & 'anlasiaa & kanlasia \\
\hline
\end{tabular}

Table 3. Voice system in Saisiyat

\begin{tabular}{|c|c|c|c|}
\hline \multicolumn{2}{|c|}{ Voice } & I (declarative) & II (imperative) \\
\hline \multicolumn{2}{|c|}{ AV } & m-, $<$ om>, ma-, ø, mo- & $\varnothing$ \\
\hline \multirow{2}{*}{ NAV } & $\mathrm{PV}$ & -en & -i \\
\cline { 2 - 4 } & $\mathrm{I} / \mathrm{BV}^{7}$ & si- & -ani \\
\hline
\end{tabular}

7In some literature, I/BV is also called UVC (Circumstantial Undergoer Voice) or RF (Referential focus). 
Saisiyat exhibits subject-verb agreement. The case marker indicates the relationship between argument(s) and predicate. Also, the theta-role of the Nominative argument is related to the voice of verb. For example, the nominative argument receives actor in the structure of $\mathrm{AV}$, as in (8a), patient in that of $\mathrm{PV}$, as in (8b), and instrument in that of $\mathrm{I} / \mathrm{BV}$, as in (8c).

8) Saisiyat [37, p.77-78]
a. $\varnothing \quad$ yaba $\quad \mathrm{S}<$ om $>$ bet $\quad \mathrm{ka}$
NOM father $<\mathbf{A V}>$ beat ACC
korkoring
child
'The father (viz actor) beats the child.'
b. $\varnothing$ korkoring ni yaba'
NOM child GEN father
Sebet-en
beat-PV
'The child (viz patient) was beaten by his father.'
c. $\varnothing$ kahoey si-Sebet ni-baki'
NOM stick I/BV ERG-grandfather
ka korkoring
ACC child
'The grandfather beat the child with the stick (viz instrument)'

The selection of voice, the case-marking mechanism, and argument licensing are closely related to syntactic structures. The following section discusses the characteristics of $\mathrm{OC}$ in Saisiyat.

\section{Object Control in Saisiyat}

\subsection{Two Types of Object Control}

Saisiyat possesses canonical and non-canonical object control constructions, whose controller and controllee present contrary distribution. This section discusses the syntactic behaviours and the distinction between the two types of OC. In Saisiyat, the combination of matrix verbs like siwa' "permit' (or talhaehael 'help', ma'alo 'thank'...) and embedded transitive verbs like kita 'see' (or sebet 'beat', raoe' 'drink', hobaan 'draw'...) or embedded intransitive verbs like 'oSa 'go' (or panra:an 'walk', hangih 'cry', sawa' 'laugh', 'ae'ae:aew 'run', pae'rem 'sleep', patol 'sing', wa:i' 'come'...) will produce object control strucutres. Due to space limitations, not all examples are listed. Take permit-type control verb for example, we inspect eight logical possibilities of $\mathrm{OC}$ formation according to the interaction of voice and the transitivity of the verb, which is atheoretically formalized in (9).

9) Logical possibilities for permit-type object control

a. $\mathrm{HE}_{(\mathrm{Nom})}$ PERMIT $_{(\mathrm{AV})} \mathrm{I}_{(\mathrm{ACC})} \operatorname{READ}_{(\mathrm{NAV})} \mathrm{BOOK}_{(\mathrm{ACC})}$
b. $\mathrm{HE}_{(\mathrm{Nom})}$ PERMIT $_{(\mathrm{AV})} \mathrm{I}_{(\mathrm{ACC})} \operatorname{READ}_{(\mathrm{AV})} \mathrm{BOOK}_{(\mathrm{ACC})}$
c. $\mathrm{HE}_{(\mathrm{Nom})} \operatorname{PERMIT}_{(\mathrm{NAV})} \mathrm{I}_{(\mathrm{ERG})} \operatorname{READ}_{(\mathrm{NAV})}$ $\mathrm{BOOK}_{(\mathrm{ACC})}$
d. $\mathrm{HE}_{(\mathrm{Nom})}$ PERMIT $_{(\mathrm{NAV})} \mathrm{I}_{(\mathrm{ERG})} \quad \operatorname{READ}_{(\mathrm{AV})}$ $\mathrm{BOOK}_{(\mathrm{ACC})}$
e. $\mathrm{HE}_{(\mathrm{Nom})}$ PERMIT $_{(\mathrm{AV})} \mathrm{GO}_{(\mathrm{NAV})} \mathrm{I}_{(\mathrm{ERG})}$
f. $\mathrm{HE}_{(\mathrm{Nom})}$ PERMIT $_{(\mathrm{AV})} \mathrm{I}_{(\mathrm{ACC})} \mathrm{GO}_{(\mathrm{AV})}$
g. $\mathrm{HE}_{(\mathrm{Nom})} \operatorname{PERMIT}_{(\mathrm{NAV})} \mathrm{I}_{(\mathrm{ERG})} \mathrm{GO}_{(\mathrm{NAV})}$
h. $\mathrm{HE}_{(\mathrm{Nom})} \operatorname{PERMIT}_{(\mathrm{AV})} \mathrm{I}_{(\mathrm{ERG})} \mathrm{GO}_{(\mathrm{AV})}$

Corresponding sentences of above logical possibilities are listed in (10). Ungrammatical sentences are marked with an asterisk "*”. The voice of embedded verb of well-formed sentences is marked by a bold font.

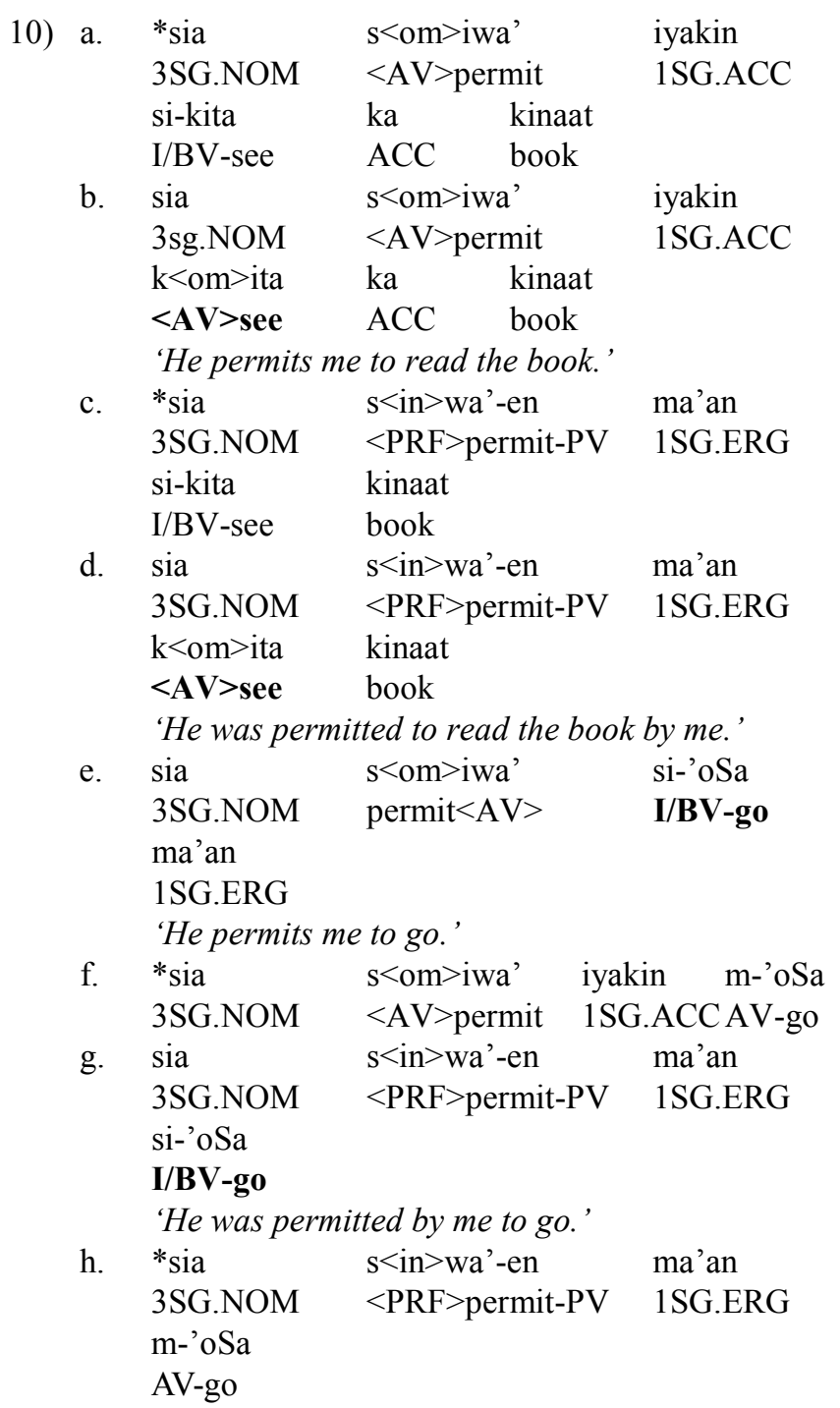

Examples in (10) illustrate that the transitive verb in an embedded clause rigorously adopts the Actor voice, while the intransitive counterpart strictly employ the Non-actor voice. It is of note that the voice of the matrix verb plays no role in the processing. Table 4 summarizes above finding. 
Table 4. The interaction of voice and transitivity in Saisiyat object control construction

\begin{tabular}{|c|c|c|c|c|}
\hline \multirow{2}{*}{ The type of OC } & \multirow{2}{*}{$\begin{array}{c}\text { Matrix } \\
\text { verb }\end{array}$} & \multirow{2}{*}{$\begin{array}{c}\text { Embedded } \\
\text { verb }\end{array}$} & \multicolumn{2}{|c|}{$\begin{array}{c}\text { Voice of embedded } \\
\text { verb }\end{array}$} \\
\cline { 4 - 5 } & & AV & NAV \\
\hline \multirow{2}{*}{ Canonical } & AV & Transitive & $\checkmark$ & $x$ \\
\cline { 4 - 6 } & NAV & Transitive & $\checkmark$ & $x$ \\
\hline \multirow{2}{*}{ Non-canonical } & AV & Intransitive & $x$ & $\checkmark$ \\
\cline { 4 - 6 } & NAV & Intransitive & $x$ & $\checkmark$ \\
\hline
\end{tabular}

These results can be attributed to the characteristics of the case-marking mechanism in Saisiyat. Many studies (see Blust[1], Chang[4], Cheng[7], Hsieh \& Huang[15] and Starosta[33,34]) show that Saisiyat is a split-ergative language. In an ergative language, also called an ergative-absolutive language, the object $(\mathrm{O})$ of a transitive verb and the single core argument $(\mathrm{S})$ of an intransitive verb present syntactic or morphological equivalence (e.g., case), while the actor (A) of transitive verb occupies different morphology. An accusative language, also called a nominative-accusative language, maintains this equivalence for the actor of transitive verb and the single core argument of an intransitive verb, while treating the object of a transitive verb differently. Saisiyat, as a split-erative language, presents the characteristics of both ergative and accusative languages. It strictly employs the Accusative-pattern of case marking in AV construction but Ergative-pattern in NAV counterpart, as given in Table $5 .{ }^{8}$

Table 5. Voice and ergativity in Saisiyat simple sentences

\begin{tabular}{|c|c|c|c|}
\hline \multicolumn{2}{|c|}{ Voice } & Case marking & Alignment \\
\hline \multicolumn{2}{|c|}{ AV } & Accusative-pattern & SA/O \\
\hline \multirow{2}{*}{ NAV } & PV & Ergative-pattern & A/SO \\
\cline { 2 - 5 } & I/BV & Ergative-pattern & A/SO \\
\hline
\end{tabular}

In Saisiyat, the object control construction also exhibits the characteristics of split-ergativity. The ergativity of the embedded verbs of object control construction can be generalized as follows: in canonical structure, the embedded verbs strictly employ the Accusative-pattern, while in non-canonical structure; the embedded verbs rigorously adopt the Ergative-pattern, as shown in Table $6 .{ }^{9}$

Table 6. Ergativity of embedded clause in Saisiyat object control

\begin{tabular}{|c|c|}
\hline Type of OC & Case marking \\
\hline Canonical type & Accusative-pattern \\
\hline Non-canonical type & Ergative-pattern \\
\hline
\end{tabular}

8Dr. H.-C. Liao reminded me that some earlier literature has argued that Saisiyat is an accusative language. In past decades, the relative research results on ergativity in Formosan languages exhibits striking discrepancies. However, recent evidence further studies increasingly support that Saisiyat is a split-ergative language.

9 Though Saisiyat presents a mix-pattern (i.e., Ergative-pattern and Accusative-pattern) in case marking, the case of the sole required argument of intransitive verbs is noted as NOM rather than NOM/ABS for conciseness. In Saisiyat, Nominative case and Absolutive case share the same morphological form.
Finally, the two types of object control in Saisiyat can be briefly formalized as (11). In canonical OC, the controller occupies a structurally higher position than the controllee, as in (11a). However, (11b) shows that, in non-canonical OC, the controller occupies a structurally lower position. Here, the controllee is atheoretically labeled with an italic " $e$ ", and controller is marked by a bold font.

11) a. canonical object control

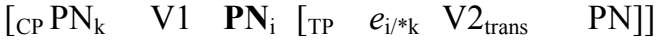

$$
\begin{aligned}
& \text { b. non-canonical object control }
\end{aligned}
$$

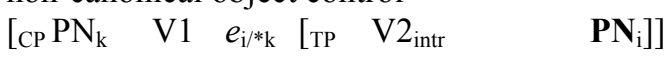

\subsection{Evidence for Non-canonical Structure}

The canonical OC is common in most languages, while non-canonical OC is relatively rare. The tests in this paper, including reciprocal, long-distance passivization, overt NP substitution, floating quantification and complementary distribution in NAV construction, support the existence of non-canonical OC in Saisiyat. In non-canonical OC, the controllee, viz covert argument, occupies a syntactically higher position than the controller (i.e., it is a linearly Right-to-Left control). The controller and the controllee denote the same reference. All the tests show that the non-canonical structure in Saisiyat undergoes a linearly Right-to-Left (or "backward") control.

Firstly, the reciprocal morphology (i.e., Ca-reduplication) in Saisiyat should be c-commanded by its antecedent in a minimal domain, as shown in (12). In example (13), lasia, or 'they,' would be the potential antecedent of the reciprocal if no null element intervened. However, the null element, which co-refers to the embedded korkoring, or 'child,' is the de facto "antecedent" of the reciprocal morphology. Reciprocal construction provides solid evidence for the existence of the null element in non-canonical $\mathrm{OC}$ in Saisiyat.

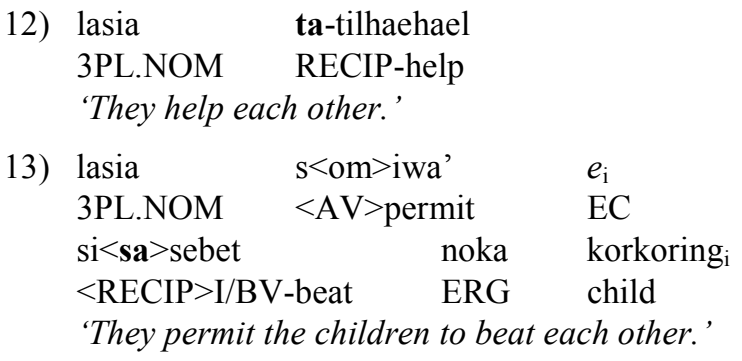

Secondly, the embedded actor moves to the subject position of the matrix clause when undergoing long-distance passivization, as in (14). If there is no null element between $m a$ 'an and si-'oSa, ma'an would be the actor of embedded verb $s i$-' $o S a$ 'go', which is contradictory as well. That is, the actor of si-' $o S a$ 'go' is sia 'he' which co-refers with null element in lower position rather than ma'an 'I.'
14) $\mathrm{sia}_{\mathrm{i}}$ $\mathrm{s}<$ in $>$ wa'-en
$<$ PRF $>$ permit-PV
ma'an
$\begin{array}{lll}\text { 3SG.NOM }<\text { si-'oSa } & <>\text { permit } \\ e_{\mathrm{i}} & e_{\mathrm{i}}\end{array}$
EC I/BV-go EC
'He was permitted to go by me.'
1SG.ERG 
Thirdly, the null pronominal can be replaced by an overt $\mathrm{NP}$ in certain contexts. Example (15) shows that though 'ataw is substituted for the null element; it maintains the co-referent relation with nisia, or 'he.' Overt NP substitution supports the validity of the null pronominal in question.

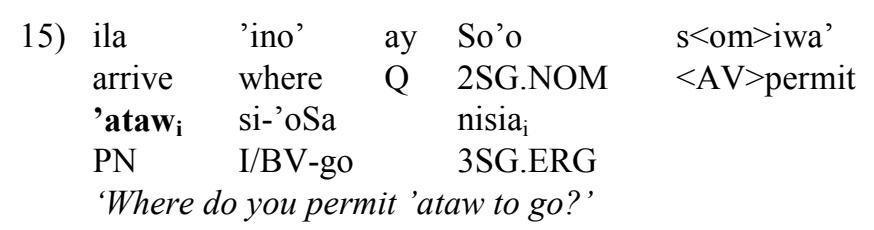

Fourthly, floating quantification indirectly illustrates that a null element exists in non-canonical OC. Usually, the universal quantifier immediately precedes to the NP it quantifies, as in (16a). Example (16b) shows that the quantifier can move to the matrix clause and be separated from the overt NP. According to my informants, the sentence is unusual but can still be accepted in certain contexts. This can be attributed to the assumption that the quantifier saboeh, or 'all,' quantifies a null element, which co-refers to the overt NP in the embedded clause.

\begin{tabular}{|c|c|c|c|c|c|}
\hline \multirow{2}{*}{\multicolumn{2}{|c|}{ 16) a. }} & $\begin{array}{l}\text { sia } \\
\text { 3SG.NOM }\end{array}$ & \multicolumn{2}{|c|}{$\mathrm{s}<\mathrm{om}>$ iwa' } & $\begin{array}{l}\text { si-'oSa } \\
\text { I/BV-go }\end{array}$ \\
\hline & & $\begin{array}{l}\text { saboeh } \\
\text { all }\end{array}$ & $\begin{array}{l}\text { noka } \\
\text { ERG }\end{array}$ & $\begin{array}{l}\text { korkoring } \\
\text { children }\end{array}$ & \\
\hline & b. & $\begin{array}{l}{ }^{\%} \text { sia } \\
\text { 3SG.NOM }\end{array}$ & $\begin{array}{l}\mathrm{s}<\text { om }>\text { iwa } \\
<\mathrm{AV}>\text { perr }\end{array}$ & & $\begin{array}{l}\text { saboeh } \\
\text { all }\end{array}$ \\
\hline & & $\begin{array}{ll}e_{\mathrm{i}} & \text { si-'oSa } \\
\text { EC } & \text { I/BV-go }\end{array}$ & $\begin{array}{l}\text { noka } \\
\text { ERG }\end{array}$ & $\begin{array}{l}\text { korkoring }_{i} \\
\text { children }\end{array}$ & \\
\hline
\end{tabular}

Finally, following example illustrates the complementary distribution between the null element and the ergative argument. There are two possible landing sites for the null element, i.e., preceding or behind the embedded verb. Non-canonical OC is formed when covert arguments occur in the position preceding the embedded verbs. As a result, the overt ergative argument ma'an, or 'I,' backward controls this null element, as in (17a). (17b) shows that the covert argument can be replaced by ma'an, which undergoes argument movement.

$\begin{array}{lllll}\text { 17) a. } & \text { sia } & \mathrm{s}<\text { om }>\text { iwa' } & e_{\mathrm{i}} & \text { si-'oSa } \\ & \text { 3SG.NOM } & <\mathrm{AV}>\text { permit } & \text { EC } & \text { I/BV-go } \\ & \text { ma'an }_{\mathrm{i}} & & & \\ & \text { 1SG.ERG } & & & \\ \text { b. } & \text { sia } & \mathrm{s}<\text { om }>\text { iwa' } & & \text { ma'an }_{\mathrm{i}} \\ & \text { 3SG.NOM } & <\mathrm{AV}>\text { permit } & & \text { 1SG.ERG } \\ & \text { si-'oSa } & e_{\mathrm{i}} & & \\ & \text { I/BV-go } & \text { EC } & & \\ & \text { 'He permits me to go.' }\end{array}$

Above tests illustrate that Saisiyat permits non-canonical, or Right-to-Left, object control. Intuitionally, if canonical and non-canonical structures are identical, above tests, e.g., long-distance passivaization and overt NP, should be possible in both. ${ }^{10}$ However, not all of above tests are allowed in canonical OC. For example, the long-distance passivization is also allowed in canonical $\mathrm{OC}$, as shown in (18). However, unlike non-canonical OC, which permits overt NP substitution, (19) shows that canonical OC does not allow this operation.

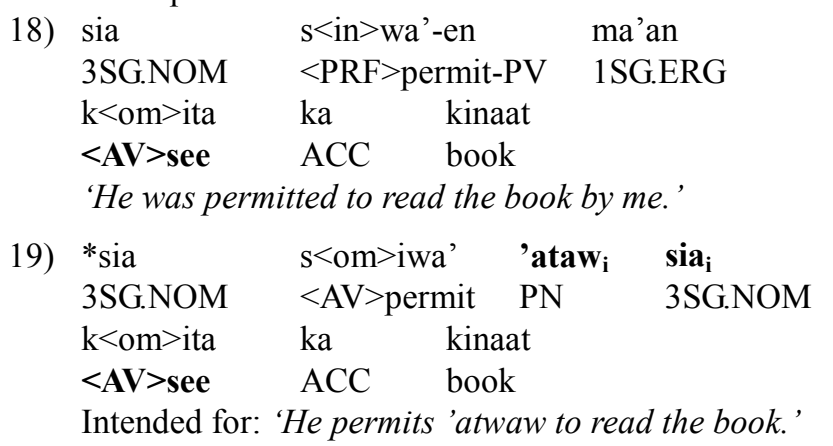

The above distinction can be attributed to the two types of OC possessing different structures ${ }^{11}$ and case-marking mechanisms. One the one hand, the controller of non-canonical OC receives an inherently ergative case. When the overt NP replaces the covert argument, this overt NP can be assigned the structural case from the matrix verb, as exemplified in (15). On the other hand, the arguments in canonical OC must be licensed by the structural case, which are assigned from the matrix verb. If covert argument is replaced by an overt NP, there will be two overt NPs competing for a single case. One of them will not receive licit licensing, which will render the sentence grammatically incorrect, as in (19). The following sections discuss the characteristics of object control in Saisiyat.

\subsection{The Characteristics of Object Control in Saisiyat}

\subsubsection{Temporal Dependency}

In Saisiyat object control construction, the temporal value of embedded clause depends on that of matrix clause. Namely, the embedded clause is atemporal. This dependency is apparent when tagging coordinate clauses behind the object control construction. Comparing (a)-(b) of (20)-(21):

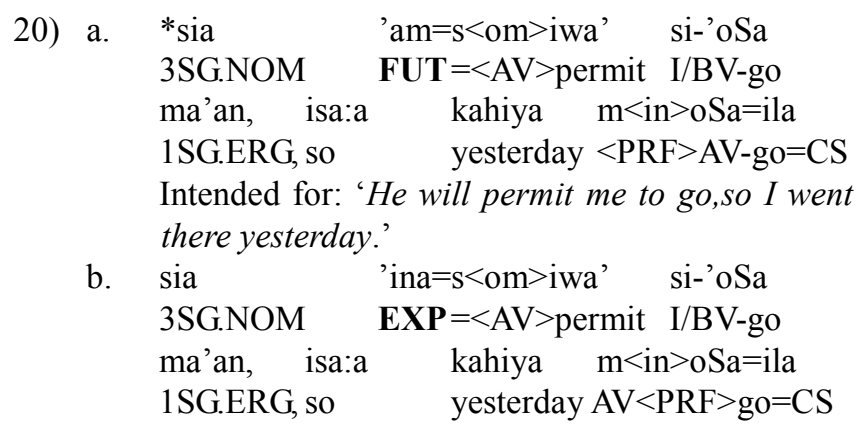

$10 \mathrm{We}$ are grateful for the reviewer's comments, which allowed us to illustrate the distinction between the two object control constructions vis-à-vis syntactic structures and behaviours.

11 We contend that syntactic behaviours are closely related to syntactic structures. The differences of syntactic structure between the two types of OC in Saisiyat will be further discussed in section 5. 


\section{'He has permitted me to go, so I went there yesterday.' \\ 21) a. *sia

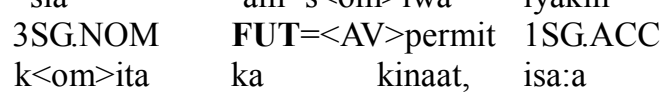 \\ $<\mathrm{AV}>$ see $\mathrm{ACC}$ book so \\ akuy $\quad \mathrm{k}<$ ini $>$ ta' - an $=$ ila \\ many $\quad<\mathrm{PRF}>$ see-LV $=\mathrm{CS}$ \\ Intended for: 'He will permit me to read books, so I read a lot.' \\ b. sia \\ 3SG.NOM $\quad \mathbf{E X P}=<$ AV $>$ permit 1 SG.ACC \\ $\mathrm{k}<\mathrm{om}>$ ita $\mathrm{ka}$ kinaat, isa:a \\ $<\mathrm{AV}>$ see ACC book so \\ akuy $\quad \mathrm{k}<$ ini $>$ ta' - an $=$ ila \\ many $<\mathrm{PRF}>$ see-LV $=\mathrm{CS}$ \\ Intended for: 'He has permit me to read books, so I read a lot.'}

The temporal value of whole object control construciton depends on that of matrix verb. To support this argument, the matrix verbs are marked by Aspect prefixes: 'am 'future' or 'ina 'experience.' Aspect marker 'am denotes irrealis reading, while 'ina indicates realis reading. We propose that the time interval taken up by the event described by a coordinate complement includes the time interval assigned to the matrix event. Thus, the ungrammaticality of (20a) and (21a) can be attributed to the temporal contradiction between OC and the following coordinate clause. Namely, in these two sentences, the temporal scope of irrealis OC does not contain that of following realis coordinate clauses. ${ }^{12}$ Conversely, (20b) and $(21 \mathrm{~b})$ shows that the temporal interval of coordinate clause includes that of matrix clause of OC, thus both sentences are grammatical. Obviously, the temporal value of embedded clause of OC play no role in above processing.

\subsubsection{Defective TP}

In Saisiyat, a single TP constitutes the embedded structure of OC. ${ }^{13}$ Some literature contends that Complementizer (C) assigns the null case to the empty pronominal in an infinitival clause. However, we argue that there is no syntacitc projection of $\mathrm{CP}$ in the embedded clause of Saisiyat object control construction. This is evidenced in the fact that there is no landing site for topicalization of the embedded argument. Comparing (a)-(b) of (22):

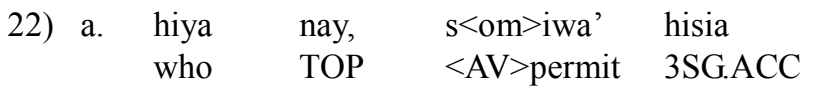

12Felser[12, p. 158] has similar finding on perception verb complement (PVC). He contends that the time interval taken up by the event described by a perception verb complement includes the time interval assigned to the matrix event (viz Simultaneity Condition on PVCs: $t_{\text {event }} \geq t_{\text {event }}$,).

$13 \mathrm{An}$ anonymous reviewer proposes that in English, embedded non-finite $\mathrm{CP}$ is possible. For example:

(i) Poirot $t_{i}$ wondered $\left[<\mathrm{CP}>\right.$ whether $\left[<\mathrm{IP}>\mathrm{PRO}_{\mathrm{i}}\right.$ to invite anyone $\left.]\right]$. (Haegeman[13], p. 269)

Thanks a lot for her/his comment, which allowed us to outline the difference between cros-linguistic syntactic structures. Thus, this section meticulously discusses the structural features of OC in Saisiyat.

\author{
$\mathrm{s}<\mathrm{om}>\mathrm{i}$ 'ael ka pazay \\ $<\mathrm{AV}>$ eat ACC rice \\ 'Who is the person that permits him to eat rice.' \\ b. *baki' $\quad \mathrm{s}<\mathrm{om}>$ iwa', hiya \\ grandfather $\quad<\mathrm{AV}>$ permit who \\ nay, $\quad \mathrm{s}<\mathrm{om}>\mathrm{i}$ 'ael ka pazay \\ TOP $<\mathrm{AV}>$ eat $\mathrm{ACC}$ rice \\ Intended for: 'Who is the person that grandfather \\ permits to eat rice.'
}

In literature, the syntactic projection of Topic is usually taken as a function head at CP layer (see Rizzi[30]). Here, nay is a common topic marker in Saisiyat. Example (22a) shows the matrix subject of OC can undergo topicalization. However, the shared argument of OC is not allowed to be topicalized, as shown in (22b). Therefore, embedded clause lacks the syntactic projection of Topic. That is, there is no $\mathrm{CP}$ layer in the embedded clause.

We contend that in Saisiyat, the embedded clause of object control construction is formed by a defective TP (or "weak" TP ). This TP exhibits [-Tense] feature, which is incapable to check uninterpreted tense feature. Therefore, aspect markers, whether realis or irrealis, cannot occur in the embedded clauses, which accounts for the ungrammaticality of (23b) and (24b).

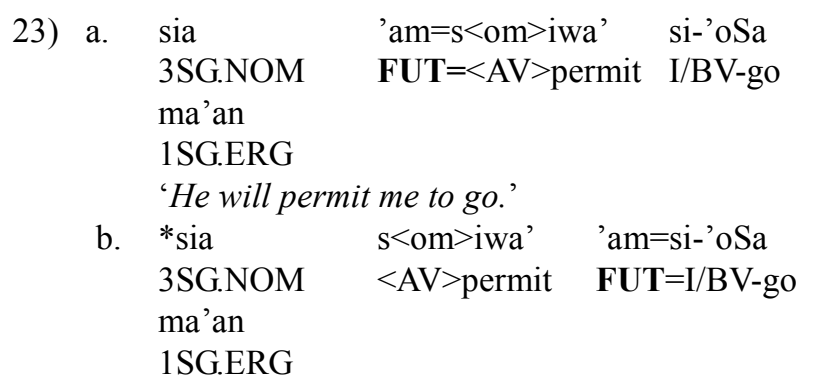

$\begin{array}{llll}\text { 24) a. } & \text { sia } & \text { 'ina }=\mathrm{s}<\text { om }>\text { iwa' } & \text { si-'oSa } \\ & \text { 3SG.NOM } & \mathbf{E X P}=<\mathrm{AV}>\text { permit } & \text { I/BV-go } \\ \text { ma'an } & & \\ & \text { 1SG.ERG } & & \\ & \text { 'He has permitted me to } \text { go.' } & \\ \text { b. } & \text { *sia } & \mathbf{s}<\text { om }>\text { iwa' } & \text { 'ina }=\text { si-'oSa' } \\ & \text { 3SG.NOM } & <\mathrm{AV}>\text { permit } & \mathbf{E X P}=\mathrm{I} / \mathrm{BV} \text {-go } \\ & \text { ma'an } & & \\ & \text { 1SG.ERG } & \end{array}$

Also, this defective TP cannot govern arguments or value case normally. (25a) shows that in a declarative sentence, $\mathrm{T}$ normally assigns the Nominative case to the actor, viz subject, of transitive verb. (25b) is ungrammatical because the embedded defective TP of OC cannot assign any licit case to the actor of embedded verb somi'ael 'eat.' The sentence is well-formed if this actor is lexically governed by the matrix verb and is assigned the Accusative case, as in (26c).

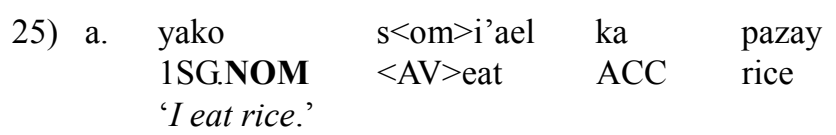




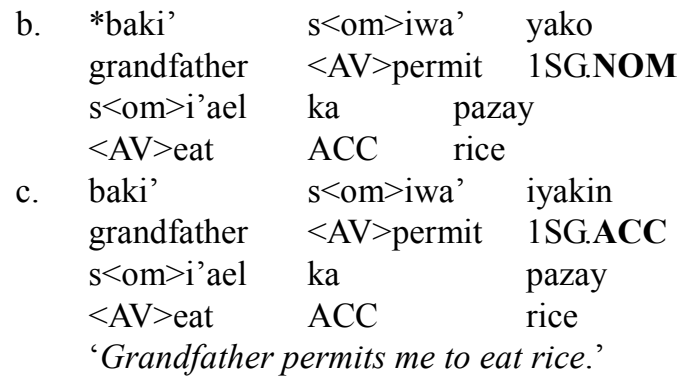

\subsubsection{Inherent and Structural Case}

Saisiyat object control construction involves two types of case-marking mechanisms: in non-canonical structure, the actor of the embedded intransitive verb receives the inherent ergative case, as in (26), while in canonical structure, the Accusative case is assigned to the actor of the embedded transitive verb, as in (27).

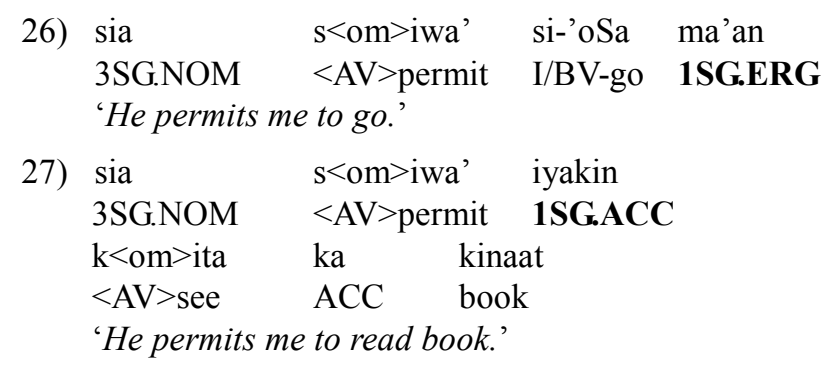

The above results can be attributed to the characteristics of defective TP discussed, which cannot govern argument and value case normally. The un-interpreted case feature of the embedded subject can be satisfied through two approaches: when embedded verb is intransitive, the argument receives the inherent ergative case. That is, it does not need to be lexically governed or be case-marked by outside governor, as in (26). However, when embedded verb is transitive, the argument has to move to the complement position of matrix verb and to be lexically governed, because the embedded defective TP cannot value case. As a result, the matrix verb assigns the Accusative case, a structural case, to this raising argument, as shown in (27).

In some situation, the actor of embedded verb even undergoes long-distance passivization to the subject position of a matrix clause and be assigned the Nominative case, as shown in (28)-(29).

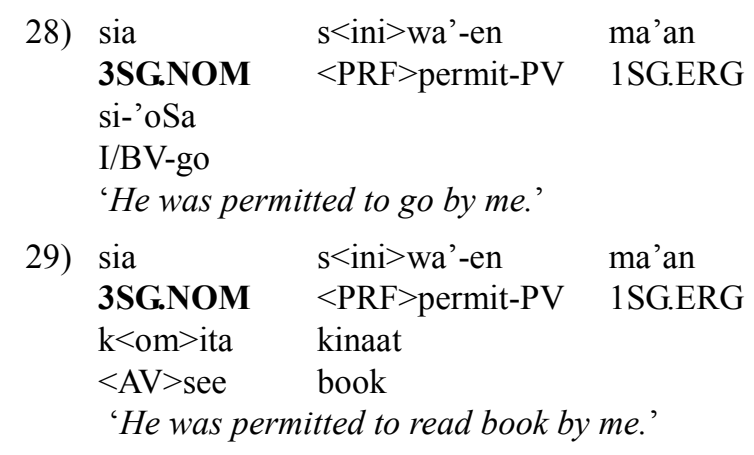

In sum, this section illustrates that the embedded clause is deficient in case-marking. Saisiyat employs two approaches to check the uninterpreted case feature of embedded arguments: When the embedded verb is transitive, the actor of embedded verb moves to the matrix clause and is assigned the structural Accusative/Nominative case. However, when the embedded verb is intransitive, the actor is base-generated in embedded clause and receives the inherent ergative case. Haegeman([13], p. 268-272) briefly discusses the distribution and characteristics of PRO. She contends that: i) PRO is the covert subject of the infinitival clause, ii) PRO must be ungoverned, iii) the weak infinitival "I" (or " $T$ " in this paper) cannot govern PRO, and this " $I$ " is not a barrier to outside governors. Though the embedded clauses of Saisiyat OC are considered as defective TP (or "weak" TP), we propose that the two types of OC are formed through argument movement and deletion. In other words, the controllee, i.e., the covert argument, is not a base-generated PRO or pro. Following section discusses the inadequacy of the base-generated approach.

\section{The Inadequacy of the Base-generated Approach}

\subsection{PRO-based Analysis}

PRO-based analysis cannot simultaneously account for both types of object control in Saisiyat, because of its ungoverned nature. In the framework of Principles and Parameters, one-to-one mapping between arguments and theta roles has to be adhere to the theta-Criterion, as proposed by Chomsky[8], which states that in a grammatical sentence, every theta role assigned by a verb must be realized by some argument, and each argument may borne only one theta role. The difference between transitive, intransitive and ditransitive verbs is decided by the number of required arguments. Sobin[32, p. 58] contends that the excessive argument in a sentence should be taken as an adjunct.

Potsdam[26,27] studied the backward object control in Malagasy and proposes some arguments to oppose the PRO-based approach (see also Polinsky \& Potsdam[25]). He contends that this approach violates other conditions contained in the framework of Government and Binding Theory. The Government and Binding Theory distinguishes three types of nominals according to two features [ \pm anaphor] and [ \pm pronominal]. This theory attributes R-expression (common noun or proper name) as [-anaphor, -pronominal], pronoun as [-anaphor, + pronominal] and reflexive pronoun as [+anaphor, -pronominal]. Three conditions (viz Condition A, B and C) account for the syntactic distribution of these three types in question. Among them, Condition B states that a pronoun can have an antecedent as long as the antecedent is not local or does not c-command the pronoun. Potsdam argues that PRO-based theory cannot successfully account for the "backward" object control construction. For instance, 
in example (7), if the empty category of the sentence were a PRO, it will incur two theoretical problems: i) the coreferential relationship cannot be established because the de fato antecedent, viz child, doesn't c-command PRO, ii) the matrix subject, Mery, cannot be the antecedent because PRO is in its local domain, which violates Condition B. However, he seems to contend that PRO is equal to a pronoun. Thus, he employs the concept of locality and c-command to illustrate that the PRO-based approach is not suitable for analyzing OC. Instead, we propose that PRO is not an anaphor and must be ungoverned. PRO does not adhere to the G\&B theory, so it is irrelevant to Condition B. ${ }^{14}$

We assert that the inadequacy of the PRO-based approach can be attributed to its ungoverned nature. Theoretically, PRO is the covert subject of infinitival and is ungoverned, and thus cannot occur in the object position, which is governed by the predicate. For example, in Saisiyat, the embedded clauses of OC are non-finite. The shared argument of OC simultaneously occupies dual theta roles: matrix patient and embedded actor. If the base-generated approach is employed, it seems to successfully account for the canonical case, as in (30a). However, example (30b) shows that PRO-based approach cannot account for Saisiyat non-canonical object control. As discussed, PRO is the subject of infinitival clause which innately is base-generated in SpecTP. This base-generated PRO cannot move to a theta-position, governed by a verb and even assigned an overt case, e.g., Nominative or Accusative. Thus, there is no ground for PRO moving to the matrix object position. In other words, PRO-based approach is not suitable for analyzing OC.

30) PRO-based analysis

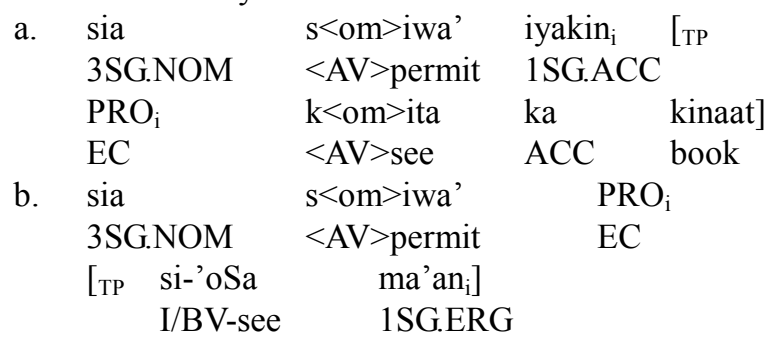

\section{2. pro-based Analysis}

pro-based approach is also unsuitable for analyzing object control in Saisiyat, because of its finite nature. Chomsky[8] proposes the concept of "empty category" to address the unpronounced nominal element or covert noun in syntax. Empty category is governed by the empty category principle (ECP) under the framework of the Government and Binding Theory. pro, with the [-anaphorical] and [+pronominal] features, is one of the empty categories. ${ }^{15}$ pro-based analysis

14Dr. W.-T. Dylan Tsai (p.c.) contends that PRO is the infinitive subject which is directly controlled by the matrix object without movement. Thus, it is impossible for PRO to be assigned by the Accusative case. Moreover, it doesn't adhere to G\&B theory because it is not an anaphor.

15The four main types of empty categories is NP-trace, Wh-trace, PRO (big is applied in some related literature. For example, Cormack $\&$ Smith[10] argue that with the empty category in Korean, an object pro-drop language, backward-control construction should be viewed as the null pronominal pro. If we follow the pro-based approach, the hypothetical structures for Saisiyat object control present as (31).

31) pro-based analysis

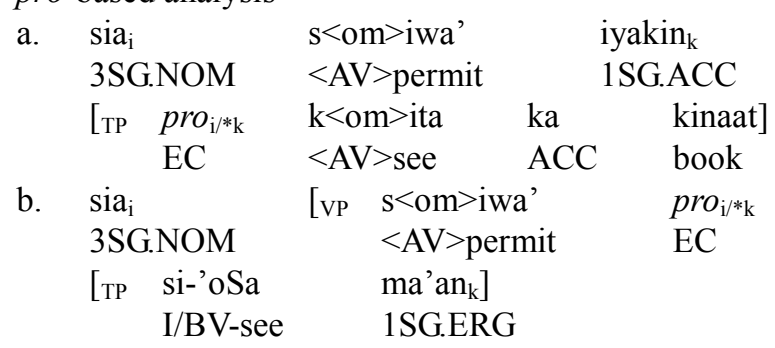

The analysis above categorically violates the nature of pro and ignores some key linguistic facts. First, C.-T. Huang[17] argues that pro belongs to the pronominal and only refers to the matrix subject of finite construction. Importantly, the object empty category cannot be co-referenced with the matrix argument cross-linguistically. Carnie[3] further asserts that little pro occurs in a subject position of a finite clause and has case. Therefore, the coreferential candidate of pro would be the matrix subject sia 'he' rather than the de facto controller (i.e., iyakin or ma'an) in both clauses of (31), which produces incorrect co-reference between arguments. Second, the nature of the embedded clause of Saisiyat object control is non-finite rather than finite. Thus, (31a) is a questionable structure because pro base-generates in a non-finite position without case assignment. pro in (31b) occurs in the object position, which is also ruled out by the requirement of subjectivity.

Moreover, Chou[9] investigates two kinds of empty categories in Saisiyat and Squliq Atayal, which is a dialect of another Formosan language. He argues that Saisiyat is not a pro-drop language. Thus, both subject pro (32a) and object pro (32b) in the embedded clause cannot refer to a matrix subject in finite contexts. In other words, there is no basis for pro-based approach.

32) Saisiyat $[9$, p. 46]

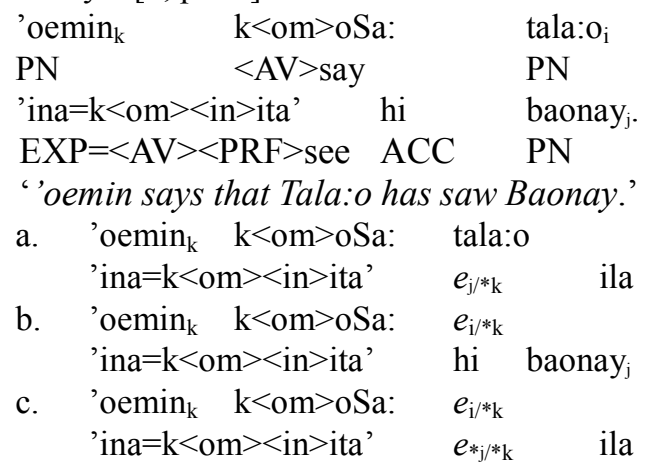

In sum, both PRO-based and pro-based approaches are inadequate for analyzing and categorizing the Saisiyat data

PRO), and pro (little pro). 
at hand. Theoretically, PRO is the covert subject of infinitival and is ungoverned, and thus cannot occur in the object position, which is governed by the predicate. Also, pro is an element of the finite clause and cannot appear in a non-finite clause. However, in Saisiyat, the embedded clauses of OC are non-finite. The shared argument of OC simultaneously occupies dual theta roles: matrix patient and embedded actor. If the base-generated approach is employed, PRO will occur in an object position, which is governed by the matrix verb, and pro will appear in a non-finite or verbal object position. Both of above situations will violate the theoretical nature of $\mathrm{PRO} /$ pro. In other words, there is no ground for these two types of base-generated analysis. Hornstein [12] proposes an alternative movement-based approach, the Movement Theory of Control, which states that control is the residue of movement [12, p. 93]. Control relation is established by the movement of an argument from one theta position to another theta position, which provides a dynamic and effective way to analyze Saisiyat OC. The following sections explore the syntactic structure of object control in Saisiyat vis-à-vis the movement-based approach.

\section{Structure Proposal and the Movement-based Approach}

\subsection{Structure Proposal}

Saisiyat is a split-ergative language. The derivation of sentences involves either the Accusative-pattern or the Ergative-pattern of case marking.

Cheng [7] describes the syntactic derivation in Saisiyat with respect to these two types of case-marking patterns. Following Cheng's argument, we consider that in the Accusative-patterns, the internal arguments merge inside the $\mathrm{VP}$, and the external arguments (EA) merge at Spec $v$ P. The transitive $v$ assigns the accusative case to the internal argument via pro-goal relations in its c-command domain. EA is assigned to the Nominative case from $\mathrm{C}$ after rising to Specifier position of TP. It is considered a bare VP for an intransitive verb if there is no internal argument. The hierarchical structure of transitive clauses in the Accusative-pattern is outlined in (33).

33) (in-)transitive clause in Accusative-pattern b.

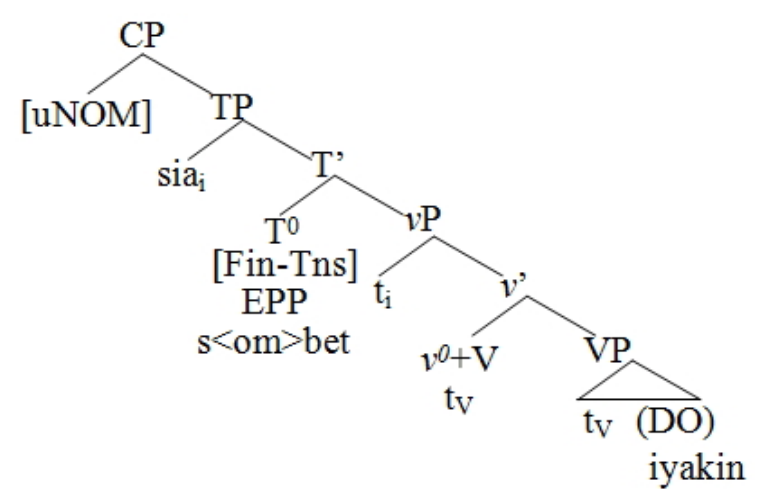

In Saisiyat, the Ergative-patterns of case marking are employed in NAV constructions. As for PV constructions, the actor of embedded verb is merged at the adjoining head of $v \mathrm{P}$ and receives the inherent ergative case. The patient moves to the Specifier position of TP and is assigned the Absolutive case, ${ }^{16}$ which possesses the same morphological form with Nominative case. Thus, this raising argument functions as the subject of the sentence, as shown in (34).
34) transitive clause in Ergative-pattern (PV)

$\begin{array}{lll}\text { a. yao } & \text { sebet-en nisia } \\ \text { 1SG.NOM beat-PV } & \text { 3SG.ERG } \\ \text { 'I was beaten by him.' } & \end{array}$

b.

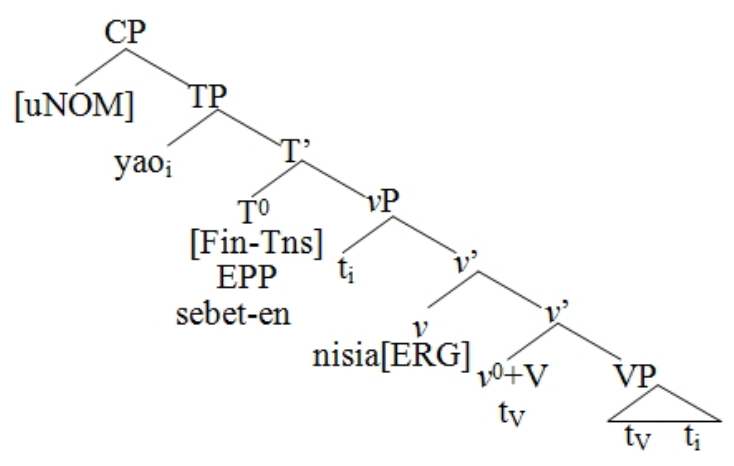

Normally, the verbs with $\mathrm{I} / \mathrm{BV}$ in Saisiyat induce an additional argument (applied object) which functions as the subject of sentence and causes verbal morphology. Marantz[20] and Pylkkänen[28] argue that double object construction can be taken as an applicative construction and when the multiple object construction relates one individual to an event, the applicative construction will be high and above VP. ${ }^{17}$ Following this line of thinking, Chen[5] and Cheng[7] apply applicative construction to account for the syntactic performance of I/BV in Formosan languages. The additional argument merges at the specifier position of high applicative phrase and then rises to SpecTP for case

16See footnote 9 .

17Furthermore, according to Pylkkänen[28], low applicative head denotes the relation between two individuals. 
licensing, as outlined in (35).

35) transitive clause in Ergative-pattern (I/BV)

$\begin{array}{lll}\text { a. } & \text { ka kahoey } & \text { si-sebet ma'an } \\ \text { NOM stick I/BV-beat } & \text { 1SG.ERG } \\ \text { hisia } & \\ \text { 3SG.ACC } & \\ & \text { 'I beat him by the stick.' }\end{array}$

b.

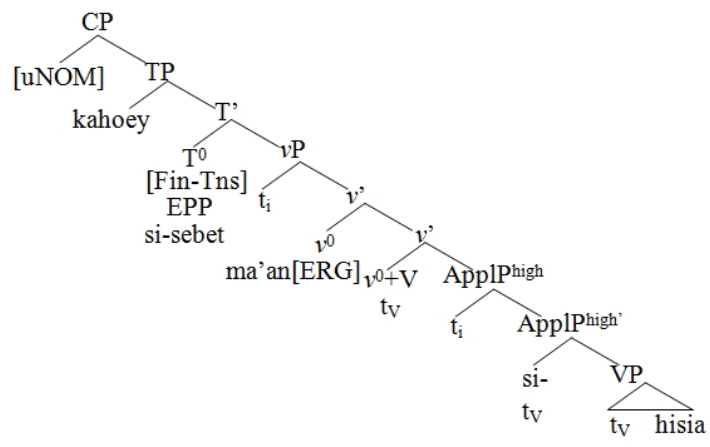

Based on previous research work (see Cheng[7], Marantz[20] and Woolford[35]), we suppose there is a function head, i.e., Applicative Phrase, for I/BV morphology. $s i$ - is the head of Appl ${ }^{\text {high }}$. It is of note that in Saisiyat, the $\mathrm{Appl}^{\text {high }}$ of the embedded clause of OC lacks an external argument (no applied argument), unlike its counterpart in normal construction. Moreover, the evidence suggests that ergative case is an inherent case (see Woolford[35]) and is base-generated at the little $v \mathrm{P}$ shell (see Rackowski[29] and Cheng[7]). Thus, the embedded hierarchical structures of the two types of OC can be depicted as (36) and (37), respectively.

36) the embedded structure of canonical OC
a. sia $\mathrm{s}<$ om $>$ iwa' iyakin
$\begin{array}{lll}\text { 3SG.NOM permit } & \text { 1SG.ACC } \\ \mathrm{k}<\mathrm{om}>\mathrm{ita} & \mathrm{ka} & \text { kinaat }\end{array}$
$\begin{array}{lll}\mathrm{k}<\text { om }>\text { ita } & \mathrm{ka} & \text { kinaat } \\ <\mathrm{AV}>\text { see } & \text { ACC } & \text { book }\end{array}$
'He permits me to read the book.'

b.

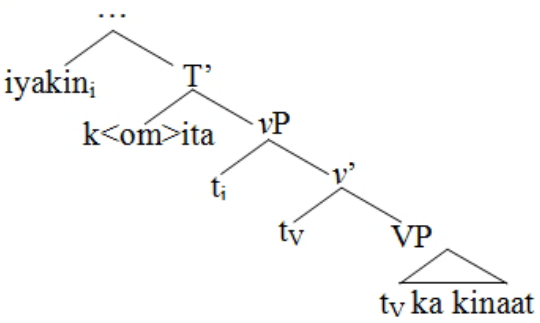

37) the embedded structure of non-canonicalOC
a. sia s<om>iwa'si-'oSa
3SG.NOM $\quad<$ AV $>$ permit I/BV-go
ma'an
1SG.ERG
'He permits me to go.'

b.

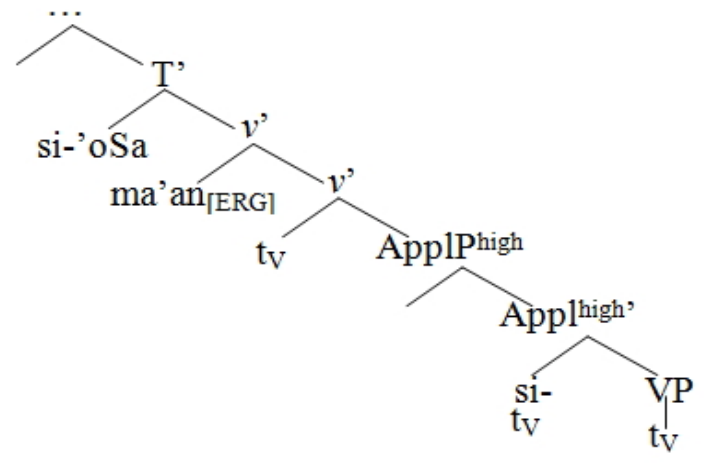

\subsection{The Movement-based Approach}

In order to have a consistent account of Saisiyat data, we turn to the movement-based approach. According to Hornstein's[14] Movement Theory of Control (MTC), control is one 'subspecies of movement.' Under MTC, every theta role is a type of feature that needs to be checked off. An argument can merge or remerge into multiple theta positions to check off every theta feature of a verb. Thus, MTC is able to account for the phenomena of arguments with multiple theta roles.

According to Hornstein, control relation is established by the movement of an argument from one theta position to another. The computation above explains why the shared argument of OC occupies dual theta roles. In order to comply with the "Last resort" and the "Greed principle" of the Minimalist Program (see Lasnik[18] and Božković[2]), the copy movement is triggered by formal features (e.g., EPP, $\varphi$-feature, etc), as proposed by Nasu[21,22], and by checking for uninterpreted features (e.g., case or tense).

Thus, the formation of OC in Saisiyat can be illustrated by (38). Initially, the embedded actor undergoes copy movement to the complement position of matrix VP. It will function as shared argument with dual theta roles. Finally, one of the copies is deleted after they achieve licit status (grammatical licensing) and are co-indexed with each other. Canonical OC is formed if the lower copy is deleted (38a). And non-canonical OC is formed when the upper copy is null at Phonological Form (38b). Here, the deleted actor and patient are atheoretically labeled by "I" and "ME", respectively.

38) a. canonical OC

$$
\begin{aligned}
& \text { sia } \quad \mathrm{s}<\text { om }>\text { iwa' } \text { iyakin }_{\mathrm{i}} \\
& \text { 3SG.NOM }<\text { AV }>\text { permit } 1 \text { SG.ACC } \\
& \text { [TP } \mathrm{I}_{\mathrm{i}} \quad \mathrm{k}<\text { om }>\text { ita } \quad \mathrm{ka} \quad \text { kinat] } \\
& \text { EC }<\mathrm{AV}>\text { see ACC book }
\end{aligned}
$$

b. non-canonical OC

$$
\begin{aligned}
& \text { sia } \quad \mathrm{S}<\text { om }>\text { iwa' } \quad \mathrm{ME}_{\mathrm{i}} \\
& \text { 3SG.NOM }<\text { AV }>\text { permit } \quad \text { EC } \\
& \text { [TP } \left.\quad \text { si-'oSa } \mathbf{m a}^{\prime} \mathbf{a n}_{\mathrm{i}}\right] \\
& \text { I/BV-go 1SG.ERG }
\end{aligned}
$$

Potsdam[26] contends that DP can be assigned multiple case feature values, with each subsequent value overwriting 
the previous one (Multiple case checking, MCC). The mechanism of copy-deletion is supported by Nunes'[23] Chain reduction principles which states that only one copy can be pronounced, and the copy with the fewest unchecked features is the copy that is pronounced. Accordingly, in canonical OC, the lower copy with uninterpreted case feature is deleted because the defective TP in embedded clause cannot assign a Nominative case to it, as illustrated in (39).

39) canonical type

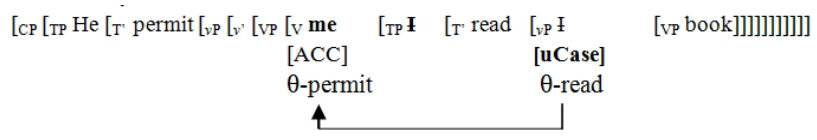

However, under Chain reduction principles, in non-canonical OC, the two copies are equal because there are no unchecked features. In fact, the realization of the upper copy is finally ruled out due to the considerations of subject-verb agreement, which states that the embedded verb with non-actor voice obligatorily chooses an overt NP with an inherent ergative case acting as its actor. Accordingly, there is no ground for the base-generated ergative argument to be deleted, as shown in (40).

40) non-canonical type

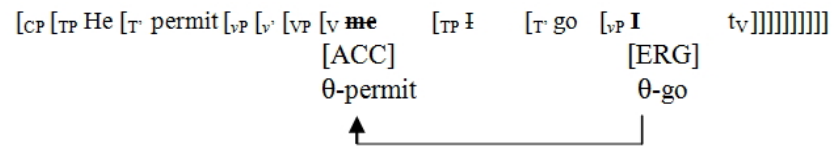

As mentioned earlier, intransitive verbs in the embedded clause of OC only adopt NAV form. Intransitive verbs only employ the Ergative-pattern of case marking. The actor of the embedded intransitive predicate must be specified by a base-generated ergative argument. Thus, in order to comply with subject-verb agreement conditions, the realization of the upper copy is ruled out. Thus, the realization of the upper copy in non-canonical OC is impossible. Please compare following sentences.

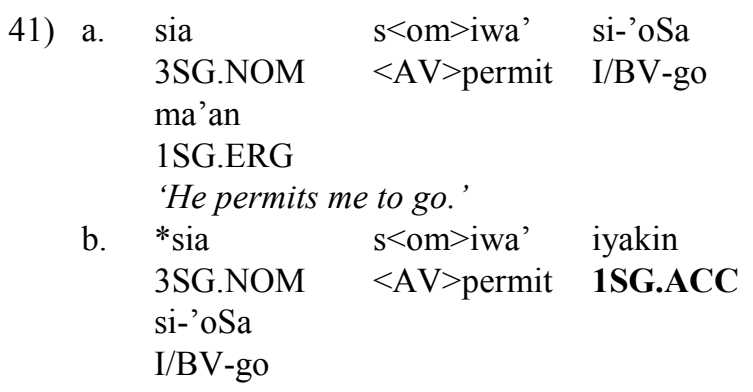

We propose that the embedded verb with non-actor voice obligatorily chooses an overt NP with the [+CAUS] feature acting as its actor. Accordingly, there is no ground for the base-generated ergative argument to be deleted. Thus, the upper copy is deleted (null at PF). The intuition of the native speaker supports this analysis. My informants state the problem of (41b) lies in the fact that in the actor of $s i$ - 'oSa 'go' is not specified. Neither sia 'he' or iyakin 'me' can be the actor of $s i$-'oSa 'go.'

As given in (42b), the similar construction with the embedded verb employing the actor voice will form a subject control construction, though this is irrelevant to our discussion. We leave this issue for further study.

42) Saisiyat $^{18}[37$, p. 136]

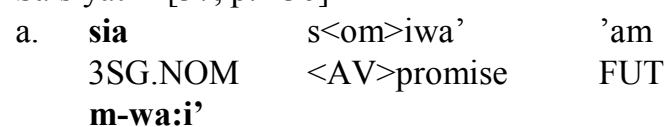

$\mathrm{AV}$-come

'He promises to come.'
b. baki' $\mathbf{s}<$ om $>$ iwa' hilasia
grandfather $<\mathrm{AV}>$ promise $\quad$ 3PL.ACC
mo-bay ka 'ahoe' ka
AV-give ACC dog ACC
korkoring

child

'Grandfather promises them that he will give the dog to the child.'

\section{The Hierarchical Structure and Syntactic Derivation}

\subsection{Canonical Object Control}

According to the discussion in previous sections, the syntactic derivation of canonical object control construction in Saisiyat can be outlined as (43).

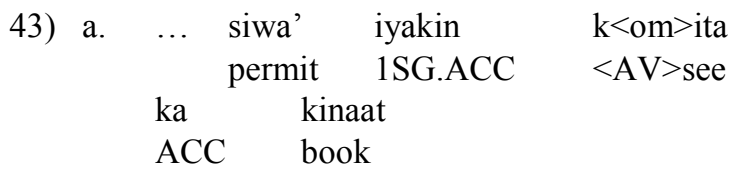

b.

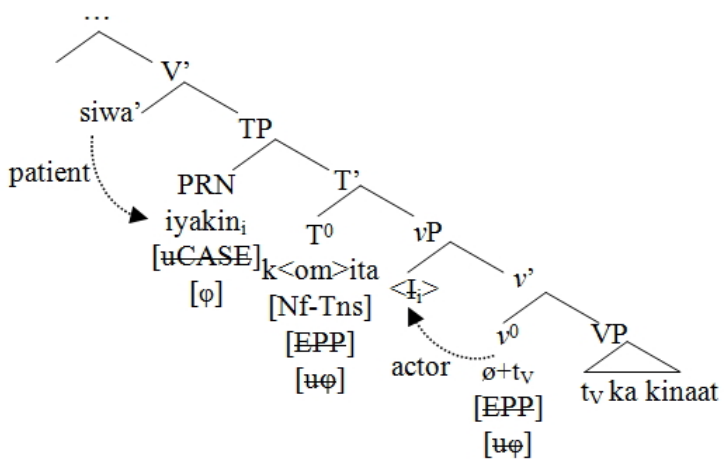

The computation of canonical OC occurs as follows: first, the embedded verb undergoes V-to-T movement for tense checking in a successive-cyclic fashion. On $v \mathrm{P}$, both the raising verb and base-generated argument agree by spec-head relation. Thus, the null head on $v$ assigns the theta role (here, actor) to the argument. In the meantime, there is

18 Yeh[37, p. 136]contends such construction is a kind of serial verb construction (SVC). Due to space considerations, we let the issues with respect to the distinction between subject control and SVC in Saisiyat for further study. Here, it is tentatively taken as subject control construction. 
corresponding agreement morphology on the verb (here, Actor voice). Second, the verb moves to the head of TP and checks the non-finite tense feature on the defective T. Along the line of MTC, the embedded actor moves (copy movement) to the SpecTP for EPP checking. Third, the case feature of the raising argument cannot be interpreted at SpecTP because the defective $T$ cannot assign licit case. However, the matrix verb lexically governs the raising argument and assigns to it the Accusative case, following the Earliness Principle (see Pesetsky[24]). Finally, following Chain reduction principles (see Nunes[21]), the lower copy goes unpronounced.

\subsection{Non-canonical Object Control}

We propose that the embedded clauses of the object control construction, whether canonical or non-canonical, are defective TP. The distinction between the two types of $\mathrm{OC}$ lie in the fact that non-canonical $\mathrm{OC}$ has additional syntactic projection of the Applicative Phrase, which makes it exhibit specific case-marking, voice selection and subject-verb agreement characteristics. Thus, the two types of OC thus exhibit different syntactic behaviours. The characteristics of applicative construction in non-canonical OC have been elaborately discussed in section 5.1. Therefore, the syntactic derivation of the non-canonical object control can be outlined as (44).

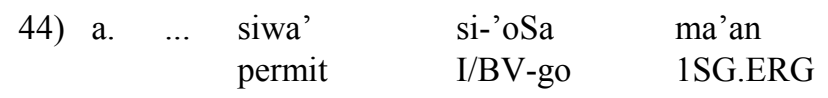

b.

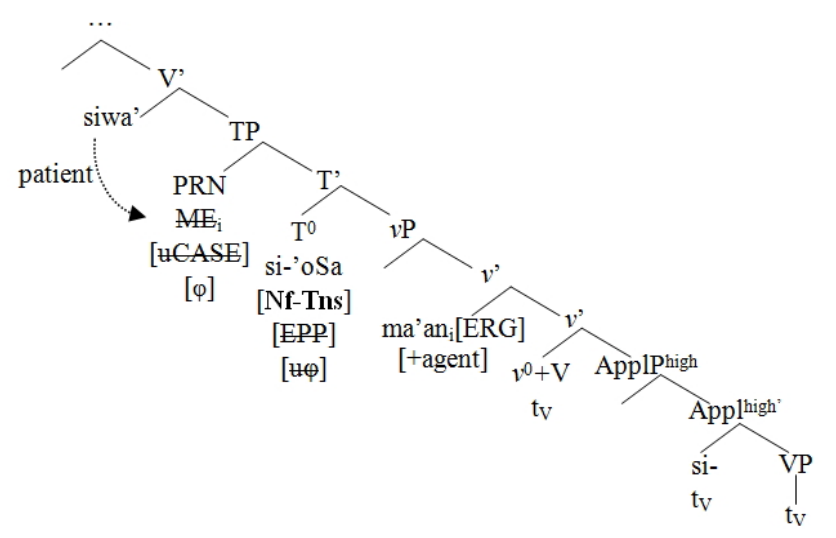

The computation of canonical object control occurs as follows: First, the embedded verb undergoes V-to-T movement for non-finite tense checking in a successive-cyclic fashion, and an inherent ergative argument is base-generated at the little $v \mathrm{P}$ shell. On $v \mathrm{P}$, both the moved verb and base-generated argument agree through spec-head relation. Thus, the null head on $v$ assigns the theta role (here, actor) to the argument. In the meantime there is a corresponding verbal morphology (here, Actor voice). Second, the verb moves to the head of TP and checks the non-finite tense feature on the defective $T$. The embedded actor also moves to the specifier position of TP for EPP checking. Third, the raising argument cannot be well-governed in an embedded clause because the defective $\mathrm{T}$ cannot assign licit case. However, the matrix verb lexical governs the raising actor and assigns to it the accusative case, following the Earliness Principle. Finally, the two copies are considered as 'equal' under Chain reduction principles. However, the upper copy is deleted due to the considerations of subject-verb agreement, which states that the embedded verb with non-actor voice obligatorily chooses an overt NP with an inherent ergative case acting as its actor. Accordingly, there is no ground for the base-generated ergative argument to be deleted. That is, only base-generated ergative arguments can be the actors of embedded verbs in OC construction.

\section{Conclusions}

This paper describes the syntax-semantic properties of object control construction in Saisiyat. Object control construction exhibits unique features, including s-selecting, embedded defective TP, shared argument with dual theta role and trivalency predicate, which distinguishes it from similar structures. Saisiyat has two types of object control: in the canonical case, the controller occupies a structurally higher position than the controllee. The transitive verb of embedded clause must adopt actor voice. In non-canonical case, the controller occupies a structurally lower position than the controllee. The intransitive verb of embedded clause only appears as non-actor voice. Reciprocal usage, long-distance passivization, NP substitution, floating quantification and free word order support these assertions of non-canonical OC in Saisiyat.

The syntactic distinction between canonical and non-canonical OC can be attributed to default structures. Saisiyat exhibits split-ergativity. Therefore, the voice selection and case assignment is related to the case marking patterns. In Saisiyat, the embedded intransitive verbs of OC strictly employ Ergative-patterns (NAV), while transitive verbs rigorously adopt the Accusative-pattern (AV). We propose that non-canonical $\mathrm{OC}$ has additional syntactic projection of Applicative Phrase in embedded clause, which makes it syntactically different from canonical OC.

We argue that PRO-based and pro-based analyses will give rise to misunderstandings vis-à-vis the nature of the empty category itself. Theoretically, PRO is the covert subject of infinitival and is ungoverned, and thus cannot occur in the object position, which is governed by the predicate. Also, pro is an element of the finite clause and cannot appear in a non-finite clause. However, in Saisiyat, the embedded clauses of $\mathrm{OC}$ are non-finite. If the base-generated approach is employed, PRO will occur in an object position, which is governed by the matrix verb, and pro will appear in a non-finite position. Instead, according to Movement Theory of Control (Hornstein[14]) and Chain reduction principles (Nasu[21,22]), we propose that the two types of OC are formed through argument movement and 
deletion. That is, the controllee, viz the covert argument, is not a base-generated PRO or pro. The argument moves from a theta position of the embedded clause to a different theta position of the matrix clause. This computation explains why the shared argument of OC occupies dual theta roles. In order to comply with the "Last resort" and the "Greed principle" of the Minimalist Program (see Božković[2], Lasnik[18]), we further propose that the syntactic operation of copy movement is triggered by formal features (e.g., EPP, $\varphi$-feature, etc), as proposed by Nasu[21,22], and by checking for uninterpreted features (e.g, case or tense). The mechanism to delete the upper copy or lower copy is successfully accounted for by Chain reduction principles and subject-verb agreement conditions.

\section{REFERENCES}

[1] Blust, Robert. Subgrouping, circularity and extinction: some issues in Austronesian comparative linguistics. In: Elizabeth Zeitoun and Paul Jen-kuei Li, editors. Selected Papers from the Eighth International Conference on Austronesian Linguistic. Taipei: Academia Sinica, 31-94, 1999.

[2] Bošković, Željiko. Case properties of clauses and the greed principle. Studia Linguistica, Vol.49, No.1, 32-52, 1995.

[3] Carnie, Andrew. Syntax: A Generative Introduction. Wiley-Blackwell, West Sussex, 2013.

[4] Chang, Henry Yung-li. AF verbs: transitive, intransitive, or both. In: Lin et al, editors. Papers in Honor of professor Hwang-Cherng Gong on His Seventieth Birthday: Language and Linguistics monograph series number 4. Taipei: Institute of Linguistics, Academia Sinica, 95-120, 2004.

[5] Chen, Sih-wei. Applicative Constructions in Atayal. M.A. thesis, National Tsing Hua University, Hsinchu, Taiwan, 2007.

[6] Chen, Yi-Ting. A Minimalist Approach to Amis Structure and Complementation. Ph. D. Dissertation, Arizona State University, US, 2008.

[7] Cheng, Yi-mei. On Transitivity and Ergativity in Saisiyat. M.A. thesis, National Tsing Hua University, Hsinchu, Taiwan, 2011.

[8] Chomsky, Noam. Lectures on Government and Binding. Dordrecht: Foris, 1981.

[9] Chou, Yi-ming Marc. The distribution and reference of empty pronou in Formosan languages. In: Ludmila Veselovská, Jeffrey K. Parrott and Markéta Janebová, editors. Proceedings of the 5th Central European Conference in Linguitics for Postgraduate Students. Department of English and American Studies, Faculty of Arts, Palacký University, Olomouc, Czech Republic, 43-57, 2016.

[10] Cormack, Annabel, and Neil Smith. Backward control in Korean and Japanese. University College of London Working Papers in Linguistics, Vol.16, 57-83, 2004
[11] Culicover, P. Principles and Parameters: An Introduction to Syntactic Theory. Oxford University Press, 1997.

[12] Felser, Claudia. Perception and control: A Minimalist analysis of English direct perception complements. Journal of Linguistics, Vol.34, 351-385, 1998.

[13] Haegeman, Liliane. Introduction to government and binding theory. $2^{\text {nd }}$ Edition. Oxford: Blackwell, 1994.

[14] Hornstein, Norbert. Movement and control. Linguistic inquiry, Vol.30, No, 1, 69-96, 1999.

[15] Hsieh, Fuhui and Shuanfan Huang. The pragmatics of case marking in Saisiyat. Oceanic Linguistics, Vol.45, No.1, 91-109, 2006.

[16] Hsieh, Fuhui and Shuanfan Huang. Saisiyat as a split ergative language. Submitted.

[17] Huang, C.-T. James. Between Syntax and Semantics. London: Routledge, 2010.

[18] Lasnik, Howard. Last resort. In: S. Haraguchi and M. Funaki, editors. Minimalism and linguistic theory. Hituzi Syobo publishing, 1-32, 1995.

[19] Li, Paul Jen-kuei. A comparative vocabulary of Saisiyat dialects. In P. Jen-kuei Li, editor. Bulletin of the Institute of History and Philology, Vol.49, No,2. Taipei: Academia Sinica, 133-199, 1978. [In Chinese].

[20] Marantz, Alec. Case and licensing. In Eric J. Reuland, editor. Arguments and case: Explaining Burzio's generalization. Philadelphia: John Benjamins, 11-30, 2000.

[21] Nasu, Norio. Associating EPP with phi-completeness. Proceedings-NELS, 351-368, 2001.

[22] Nasu, Norio. Aspects of the Syntax of A-movement: A study of English Infinitival Constructions and Related Phenomena. Ph.D. dissertation, University of Essex, UK, 2002.

[23] Nunes, Jairo. Linearization of Chains and Sideward Movement. Cambridge, MA: MIT Press, 2004.

[24] Pesetsky, David. Zero Syntax: Experiencers and Cascades. Cambridge, MA: MIT Press, 1996.

[25] Polinsky, Maria, and Eric Potsdam. Backward control: evidence from Malagasy. MIT Working Papers in Linguistics, Vol.44, 257-272, 2002.

[26] Potsdam, Eric. Malagasy Backward object control and principles of chain reduction. Ms., University of Florida, 2006.

[27] Potsdam, Eric. Malagasy backward object control. Language, Vol.85, No.4, 754-784, 2009.

[28] Pylkkänen, Liina. Introducing Argument. Ph.D, dissertation, Massachusetts Institute of Technology, US, 2002.

[29] Rackowski, Andrea and Norvin Richards. Phase edge and extraction: a Tagalog case study. Linguistic Inquiry, Vol.36, 565-599, 2005.

[30] Rizzi, Luigi. The fine structure of left periphery. In L. Haegeman (ed.). Elements of Grammar: Handbook in Generative Syntax. Dordrecht: Kluwer, 281-338, 1997. 
[31] Rosenbaum, Peter Steven. The Grammar of English Predicate Complement Constructions. Ph.D. dissertation, Massachusett s Institute of Technology, US, 1965.

[32] Sobin, Nicholas. Syntactic Analysis The Basics. Blackwell Publishing, 2011.

[33] Starosta, Stanley. A grammatical typology of Formosan languages. In: Elizabeth Zeitoun, editor. Bulletin of the Institute of History and Philology, Vol.59, No2, Taipei: Academia Sinica, 541-576, 1988.

[34] Starosta, Stanley. Formosan clause structure: transitivity, ergativity, and case marking. In: Chiu-yu Tseng, editor. Chinese Languages and Linguistics IV: Typological Studies of Languages in China. Taipei: Academia Sinica, 125-154, 1997.

[35] Woolford, Ellen. Lexical case, inherent case, and argument structure. Linguistic inquiry, Vol.37, No.1, 111-130, 2006.

[36] Wu, Ching-lan. Amis Complex Constructions. M.A. thesis, National Taiwan Normal University, Taipei, Taiwan, 1995.

[37] Yeh, Marie M. A Reference Grammar of Saisiyat. Series on Formosan Language 2. Taipei: Yuanliou, 2000. [In Chinese]

[38] Yeh, Marie M. A Syntactic and Semantic Study of Saisiyat Verbs. Ph.D. dissertation, National Taiwan Normal University, Taipei, Taiwan, 2003.

iI am grateful to the following informants of northern (Da'ai) Saisiyat: Bo:ong a Tahes, Paeaeh a Obay and especially Obay a Oemaw. Particular thanks go to Aubrey K. Thibaut, Elizabeth Zeitoun, Henry Y. Chang, Hsiu-Chuan Liao, T. -H. Jonah Lin and Wei-Tien Dylan Tsai (sort by name) for their instructive comments and discussions. I am also indebted to the anonymous reviewers and the audience at NWLC-2014 (Simon Fraser University) who raised important questions and suggestions that helped clarify a few points in this paper. Needless to say, all errors and misinterpretations of the Saisiyat data remain my responsibility. 